\title{
Sequência didática: o gênero oral argumentativo e o debate regrado
}

\section{Teaching sequence: argumentative oral gender and ruled debate}

\author{
Aleandra Ribeiro de Araújo ${ }^{1}$
}

\begin{abstract}
Resumo
O presente artigo versa o relato de experiência da prática docente realizada na Escola Estadual de Ensino Fundamental Domingos Perim, na turma de Ensino Fundamental $9^{\circ}$ V01, localizada no município Venda Nova do Imigrante, estado do Espírito Santo. As aulas, no total de quatro, foram realizadas sequencialmente duas a duas. 0 tema abordado nas aulas foi o gênero oral argumentativo na modalidade debate regrado, que teve por ponto de reflexão a gravidez na adolescência. Os principais resultados encontrados indicaram que os professores devem apropriar-se das teorias referentes à aprendizagem, das normativas constantes nas políticas governamentais e dos livros didáticos que estão disponíveis para os auxiliar no dia a dia na sala de aula, para a elaboração de uma aula participativa e interativa. Constatou-se também que é imprescindível que o professor trabalhe em sala de aula interdisciplinarmente questões sociais relevantes, como a gravidez na adolescência, uma vez que se espera que a formação da sala de aula extrapole os muros escolares e signifique melhoria na qualidade de vida dos alunos e alunas, como também de toda a sociedade. As principais bases teóricas para tais conclusões foram Schneuwly \& Dolz (2011), Cereja \& Cochar (2018), como também as normativas da BNCC (2017).
\end{abstract}

Palavras-chave: Sequência Didática. Gênero Oral Argumentativo. Debate.

\begin{abstract}
This article deals with the experience of teaching practice held at the Domingos Perim State Elementary School, in the 9th V01 Elementary School, located in the municipality of Venda Nova do Imigrante, state of Espírito Santo. As classes, a total of four, they were held sequentially two by two. The theme addressed in class was the oral argumentative genre in the regulated debate modality, which had adolescent pregnancy as a point of reflection. The main results found indicated that teachers should appropriate the theories related to learning, the norms contained in public policies and the textbooks that are available to assistants in their daily lives in the classroom, for the preparation of a participatory class. and interactive. It was also found that it is essential that the teacher works in the classroom in interdisciplinary relevant social issues, such as teenage pregnancy, quality since it is expected that the formation of the classroom goes beyond the school walls and means improvement in the lives of students and students, as well as the whole of society. The main theoretical bases for such were Schneuwly \& Dolz (2011), Cereja \& Cochar (2018), as well as the regulations of the BNCC (2017).
\end{abstract}

Keywords: Didactic Sequence. Oral Argumentative Genre. Ruled Debate.

\section{Introdução}

O presente relato de experiência visa descrever minuciosamente a docência compartilhada e a regência de sala de aula. Ela foi realizada na EEEF Domingos Perim, na turma $9^{\circ} \mathrm{V} 01$, como requisito avaliativo da disciplina Estágio Supervisionado Anos Finais Ensino Fundamental II, pertencente ao Curso Superior Letras - Português do Instituto Federal de Educação, Ciência e Tecnologia da Espírito Santo.

\footnotetext{
1 Graduanda em licenciatura Letras-Português. Instituto Federal de Educação, Ciência e Tecnologia do Espírito Santo, Campus Venda Nova do Imigrante, Espírito Santo, Brasil. Orcid: https://orcid.org/0000-0001-5266-2928. E-mail: alevendanova@gmail.com
}

LínguaTec, Instituto Federal de Educação, Ciência e Tecnologia do Rio Grande do Sul, Bento Gonçalves 
O trabalho com o gênero oral debate regrado justifica-se devido à sua relevância para o pleno exercício da cidadania, estando presente no Eixo da Oralidade da Base Nacional Curricular Comum BNCC (2017). Esse eixo, segundo o documento, compreende as práticas de linguagem que ocorrem em situação oral a partir do contato face a face, com aula dialogada, webconferência, mensagem gravada, spot de campanha, jingle, seminário, debate, programa de rádio, entrevistas, dentre outras. Envolve também a oralização de textos em situações socialmente significativas, interações, discussões envolvendo temáticas e outras dimensões linguísticas do trabalho nos diferentes campos de atuação (BNCC, 2017, p.79).

A Base Nacional Comum Curricular (BNCC) é um documento:

de caráter normativo que define o conjunto orgânico e progressivo de aprendizagens essenciais que todos os alunos devem desenvolver ao longo das etapas e modalidades da Educação Básica, de modo a que tenham assegurados seus direitos de aprendizagem e desenvolvimento, em conformidade com o que preceitua o Plano Nacional de Educação (PNE). Este documento normativo aplica-se exclusivamente à educação escolar, tal como a define $0 \S 1^{\circ}$ do Artigo $1^{\circ}$ da Lei de Diretrizes e Bases da Educação Nacional (LDB, Lei $n^{0}$ 9.394/1996)1, e está orientado pelos princípios éticos, políticos e estéticos que visam à formação humana integral e à construção de uma sociedade justa, democrática e inclusiva, como fundamentado nas Diretrizes Curriculares Nacionais da Educação Básica (DCN) (BNCC, 2017, p. 7)

Segundo Santos (2009), o gênero debate tem sido, ao longo dos anos, objeto de interesse de vários teóricos e, assim, de detalhadas investigações, como no caso da equipe de Línguas da Universidade de Genebra nos anos de 1998 a 2004. No último ano destacado, o gênero debate foi objeto de estudo de Schneuwly e Dolz, estudiosos consagrados principalmente no que tange à sequência didática e ao uso em sala de aula dos gêneros textuais. Eles destacam que a variante escolar do debate deve privilegiar mais a construção conjunta de um ponto de vista sobre um assunto do que as dimensões polêmicas do debate (SANTOS, 2009, p. 43).

Dolz e Schneuwly apud Santos (2009) destacam que:

para que haja um debate é necessário a presença de um moderador que organiza o seu desenvolvimento demonstrando o ponto de vista de diferentes debatedores (participantes), oportunizando a transição entre suas falas, evitando conflitos e assim priorizando a conciliação de posições contrárias visando o enriquecimento do evento linguístico (SCHNEUWLY; DOLZ apud SANTOS, 2009, p. 43).

Em suma, os estudiosos definem que, para um debate regrado, alguns pontos devem ser seguidos, como: a presença de um argumento que dará início ao debate; concordâncias, aprofundamento, desacordo e refutação; e utilização de exemplos, experiências, leis etc. para refutar as ideias. 
Diante 0 exposto, a presente sequência didática sobre o gênero debate regrado foi organizada no que os teóricos Dolz e Schneuwly apresentam. Pressupõe-se, portanto, as seguintes fases de execução: argumentação inicial de um tema polêmico que possui ideias discordantes; embasamento dos/as alunos/as sobre o tema (bons argumentos); regras para o debate; e um fechamento conclusivo, mesmo que sem consenso, com a produção de um vídeo realizado pelos/as alunos/as sobre o debate vivenciado na sala de aula.

Nesta sequência didática, escolhemos trabalhar o gênero oral debate regrado voltado aos alunos/as cursantes do nono ano do ensino fundamental na EEEF Domingos Perim, durante quatro aulas de cinquenta minutos cada. $O$ objetivo principal desta sequência foi aprimorar o conhecimento dos/as alunos/as acerca do gênero em questão, bem como estimulá-los à argumentação e ao desenvolvimento da oralidade.

Iniciamos 0 assunto em duas aulas sequenciais, que foram utilizadas para introduzir a temática. Na primeira aula, realizamos uma exposição do tema debate regrado, primeiramente com a aplicação da técnica tempestade de ideias, a fim de verificar o que os/as alunos/as sabiam sobre o gênero debate; $\mathrm{e}$ em seguida deu-se a aula expositiva sobre o tema. Nesse momento, foram abordados o conceito do debate regrado, os seus principais tipos, a diferença entre debate e briga, os elementos necessários para um bom debate, as funções do moderador, dos secretários e dos participantes, e a formação de argumentos sendo utilizados para tal em vídeos, reportagens, artigos científicos, gibi, dentre outros.

Após essa abordagem teórica, os/as alunos/as se organizaram para as duas aulas finais da sequência didática e iniciaram a prática do debate regrado sobre o tema gravidez na adolescência. $A$ turma foi dividida em dois grupos, um contra e outro a favor. A divisão nesses dois grupos ocorreu após ser percebido que mesmo após eles terem estudado sobre o tema em aulas anteriores e produzido uma redação, percebeu-se uma divisão entre aqueles que eram a favor da gravidez por ser uma questão presente em sua família ou meio social, e aqueles que criticavam por acreditar que era responsabilidade apenas da adolescente e não do casal. Assim, convencionou-se que o grupo contra a gravidez na adolescência deveria, a partir das leituras propostas para a atividade, desenvolver argumentos que assinalassem os danos causados ao casal de pais adolescentes, com o advento de uma gravidez não planejada. Já o grupo a favor, deveria se ater a casos que conheciam na sua comunidade, ou mesmo em sua família, de uniões que se deram a partir de uma gravidez não planejada na adolescência e que se mantém de maneira sólida. 0 fato de várias alunas se manifestarem a favor da gravidez na adolescência foi explicado por elas por terem sido geradas nesse contexto, sendo acolhidas por seus familiares, mesmo não sendo nada planejado na família. As alunas também relataram casos de amigas, 
que se declaram muito felizes com o fato de terem engravidado na adolescência, por terem recebido apoio familiar e do parceiro. Isso permitiu vivenciar essa fase de forma saudável. Relataram, ainda, a importância de políticas públicas assertivas para as adolescentes que engravidam.

Para fundamentar ainda mais os argumentos dos/as alunos/as, foram selecionados vídeos que evidenciassem, com clareza e verdade, o que leva a uma gravidez indesejada, as consequências para os pais adolescentes e suas famílias (como o abandono escolar, por exemplo), relatos de pais adolescentes que moram nas mais diferentes regiões do país sobre a experiência vivenciada e muitas vezes comum no bairro e na escola, dentre outras informações. Um dos vídeos foi produzido e estrelado por alunos portugueses, sendo disponibilizado numa plataforma de compartilhamento de vídeos, denominada YouTube. Ele mostra o início do namoro de um casal de adolescentes e o drama da menina quando desconfia estar grávida. Nesse vídeo, os/as alunos/as são apresentados ao sofrimento da dúvida, do arrependimento, da frustração e do abandono que comumente estão presentes na vida de uma adolescente que se descobre numa gravidez não planejada. A finalidade da atividade era que os/as alunos/as exercitassem seus posicionamentos, sua oralidade, participação e envolvimento com temas sociais relevantes para a adolescência. Sendo assim, a atividade final proposta foi a realização de um debate regrado, marcado pelo protagonismo dos estudantes que desempenharam as funções de moderador, secretário e participante. Ao término da atividade, foi realizada uma avaliação oral das aulas apresentadas e do debate realizado, a fim de expor seus pontos de vista e os novos aprendizados adquiridos.

\section{0 gênero oral argumentativo debate regrado}

Segundo Santos (2009), o gênero debate tem sido, ao longo dos anos, objeto de interesse de vários estudiosos e, assim, de detalhadas investigações, como no caso da equipe de Línguas da Universidade de Genebra nos anos de 1998 a 2004.

No livro didático Português Linguagens, $9^{\circ}$ ano, de Cereja e Cochar (2017), ficou evidenciada a necessidade de uma organização prévia para que o debate fosse proveitoso, já que as pessoas são incentivadas a falar, porém devem seguir regras. As principais regras foram: organizar a sequência das falas e o tempo máximo de exposição; delimitar as punições em caso de agressões pessoais; definir um moderador, que será o organizador do debate. Coube ao moderador, no debate regrado: apresentar 0 tema a ser debatido; explicar as regras aos alunos, como o fato de terem direito a réplica e a tréplica para a contraposição de ideias e o fato de cada um ter o direito de fala no momento do debate para que 
todos pudessem participar; controlar o tempo dos debatedores nas suas exposições, tendo por base 0 livro didático que aborda planejamento, realização, princípios e procedimentos para a realização de um debate democrático.

\section{A Sequência didática: debate regrado}

O momento inicial da sequência didática foi direcionado a uma atividade de investigação, em que os alunos foram incentivados a descreverem oralmente o que conheciam sobre o gênero debate. Nesse momento, foi solicitado que respondessem às questões referentes aos conhecimentos prévios sobre 0 debate regrado, a frequência com que assistiam ao gênero na televisão, Facebook, YouTube ou Instagram, a finalidade do debate que assistiram (política, reivindicatória, educacional) e também se conheciam as regras de um debate.

Após essa dinâmica inicial, também chamada de "tempestade de ideias", os/as alunos/as puderam expor suas conviç̧ões sobre o tema. Nesse momento, observou-se a presença de argumentos ainda confusos, com preconceitos e ausência da responsabilização do pai adolescente, ficando somente para a mãe adolescente e para seus familiares o desafio da gravidez não planejada. Esse fato evidenciou ainda mais a necessidade da discussão desse tema.

Em sequência, deu-se início à aula expositiva sobre a importância do debate enquanto gênero na comunicação oral, também denominado módulo I - O gênero na comunicação oral. Nesse módulo, foi utilizado o livro didático indicado para o nono ano da EEEF Domingos Perim. No livro, o tema debate regrado está na Unidade 3 - Ser Jovem, no capítulo 1, no item Produção de texto, quando foi conceituado e apresentado aos/às alunos/as através da transcrição de um debate ocorrido a convite dessa coleção de livros didáticos, entre 12 jovens de 15 a 18 anos, com o tema: A violência na sociedade e as causas da violência (CEREJA; COCHAR, 2017, p. 136-137).

Após a leitura, os/as alunos/as foram direcionados a responder questões discursivas sobre 0 texto lido. Em seguida, na seção Agora é a sua vez, os/as alunos/as foram instigados a participar de um debate regrado com a mediação do professor sobre o tema: O celular na sala de aula: vilão ou evolução pedagógica? Para a realização dessa atividade, o livro foi um auxiliador aos/às alunos/as, trazendo-lhes informações sobre como deve ser planejado, organizado, seus princípios e procedimentos e forma de avaliação. Após essa fase inicial, o tema foi retomado no capítulo 2, intitulado Ser Jovem é..., e nos itens Produção de Texto e Agora é a sua vez, quando os alunos foram orientados a ler um infográfico retirado do jornal Folha de São Paulo (8/8/2011, Folhateen), seguido de três reportagens sobre o tema gravidez 
na adolescência, a fim de subsidiar um outro debate sugerido pelo livro didático (CEREJA; COCHAR, 2017, p. 160-164).

Diante do exposto, no início das aulas foi feito um breve resgate sobre o que já havia sido estudado pelos alunos no livro didático sobre o tema debate, visando elencar o que fora aprendido e 0 que ainda necessitava de aprofundamento. Com o aproveitamento dos apontamentos realizados pelos alunos nesse momento, ficará demonstrará para eles a importância do livro didático no cotidiano da sala de aula. Assim, o ponto de partida da sequência didática foi o que já havia sido abordado pelo professor com o uso do livro didático e a necessidade de oportunizar aos/às alunos/as contato com outros olhares sobre a gravidez na adolescência, seus impactos na vida dos adolescentes envolvidos, de seus familiares e também de toda a sociedade.

A primeira aula expositiva da presente sequência didática sobre o debate regrado foi iniciada a partir do que conceituam Cereja e Cochar (2017) sobre o gênero, sendo destacado que ele só se realiza em uma situação concreta de fala e interação entre pessoas. Em seguida, foi explicado para os/as alunos/as alguns tipos de debate: o político, utilizado para decidir sobre legislações, direitos e deveres dos cidadãos; o escolar, presente nas decisões sobre a comunidade escolar e o dia a dia da escola; 0 filosófico, que se debruça sobre temas do ser humano e a vida em sociedade; e o esportivo, que critica ou elogia jogadores e técnicos dentre outros assuntos. Nesse ponto da aula, os alunos perceberam que o debate se faz presente em seu cotidiano, sendo um importante exercício da língua materna e de cidadania.

Na sequência da aula expositiva, foi realizada uma reflexão com os alunos sobre o que não é um debate e se ele é igual a uma briga, uma discussão. Então, foi destacado que debater é ter o direito de expor livremente nossas ideias, bem como o dever de ouvir e respeitar as ideias alheias, mesmo que diferentes das nossas; é modificar o outro e modificar a nós mesmos; é crescer com o outro e ajudá-lo a também crescer a partir de nossa experiência e de nossa visão de mundo; é um exercício de cidadania que, independentemente do resultado, do debate a troca de argumentos é uma experiência enriquecedora tanto para quem dele participa diretamente quanto para quem o presencia. Ao final da exposição, os alunos deveriam oralmente relatar exemplos de debates que tivessem conhecimento, e relacionar o que entenderam ser necessário para que ocorra um bom debate (CEREJA; COCHAR, 2017).

Após a atividade oral, foi feita leitura comentada da página 141 do livro didático Português Linguagens, que aborda as orientações para participação do debate, organização, comportamentos esperados, sequência de situações frequentes no debate, o papel do moderador/mediador, as regras, a regulação de trocas de falas e opiniões, a necessidade de constante animação e aprofundamento do 
tema pelo moderador e, ao final, a conclusão das principais ideias debatidas. Durante a leitura, deveriam ser relacionados os pontos levantados pelos alunos somados àqueles presentes no livro didático, que são: pense sobre o tema e assuma um ponto de vista, de acordo com sua opinião sobre o assunto debatido; fundamente sua opinião com bons argumentos, com motivos e explicações; procure utilizar dados e fatos como exemplo em sua argumentação; faça anotações dos pontos principais que você defenderá e dos argumentos a serem utilizados, que podem ser guias para seu raciocínio; não fale nem muito alto, nem muito baixo, nem gritando, nem sussurrando, procure falar com segurança; evite gírias ou repetições de uma mesma expressão: "né", "tipo", "tá"...; prepare-se previamente sobre o tema, consultando a informação necessária (livros, revistas, jornais, ...); exponha com clareza as suas ideias; respeite as regras previamente estabelecidas, nomeadamente as indicações do moderador; escute atentamente, evitando repetir ideias já expostas; evite interromper quem está no uso da palavra e não utilize uma linguagem agressiva.

Já na segunda aula proposta, os/as alunos/as foram direcionados para a formação de argumentos, para que pudessem se preparar para o debate. Para tal, assistiram a dois vídeos sobre 0 tema a ser debatido: gravidez na adolescência. $O$ primeiro trata-se de uma reportagem que foi exibida em um canal de televisão aberto no programa Profissão Repórter (BARCELLOS, 2019), com a duração de 36 minutos. $O$ segundo foi produzido e estrelado por alunos/as portugueses, sendo disponibilizado numa plataforma de compartilhamento de vídeos denominada YouTube. Ao final dos vídeos, foi realizada breve reflexão sobre os principais pontos.

Após as discussões propostas, os/as alunos/as realizaram uma atividade em casa, visando aprimorar os argumentos e, assim, estarem mais confiantes para o debate programado para 0 encerramento das atividades, na última aula. Para isso, os/as alunos/as deveriam acessar a sala virtual da turma no sítio Google Sala de Aula e ali assistir, ler e ouvir os materiais inseridos sobre a temática, que foram os seguintes: Gibi Brasilzinho e a Galera Adolescente - Gravidez na Adolescência; Crônica de uma adolescente grávida aos quinze anos; Vídeo do YouTube Gravidez na Adolescência (3min 20s); áudio de uma entrevista de uma psicóloga sobre o tema; artigo científico "O Pai Adolescente"; reportagem do programa Profissão Repórter (BARCELLOS, 2019) e o vídeo sobre gravidez na adolescência já referido. Após o contato com os diferentes materiais sobre o tema, os/as alunos/as foram orientados/as a se organizarem e decidirem qual deles seria o moderador/a, os/as secretários/as e os participantes na aula em que fariam o debate.

No dia do debate, na sala de aula, organizamos as cadeiras ordenadas em círculo, sendo que três cadeiras foram dispostas juntas para o/a moderador/a e as duas secretárias. Uma delas anotou a 
fala dos participantes que relataram os pontos positivos da gravidez na adolescência, que foram: 0 apoio familiar aos pais adolescentes; as políticas públicas, que garantem consultas médicas, medicamentos e exames gratuitos e também consultas com psicólogo; o apoio recebido na escola, com a possibilidade de realizar atividades em casa no pós-parto. Foi observado que algumas adolescentes tratavam a gravidez na adolescência com naturalidade por fazer parte do seu contexto social, tendo esse fato ocorrido com sua avó, mãe e amigas. A outra secretária anotou os argumentos desfavoráveis para a adolescente que engravida destacados pelos/as alunos/as, sendo os destaques: a evasão escolar; inclusão no mercado de trabalho sem qualificação; preconceito no ambiente familiar, comunitário e educacional; ausência de políticas públicas para adolescentes. Ao final, fizeram a leitura para todos os participantes.

No tocante ao registro da aula debate, os alunos se organizaram e elegeram aqueles que fariam a filmagem para que fosse analisado e assistido posteriormente por todos. Observou-se que os/as alunos/as pontuaram questões relevantes sobre a temática do debate, destacando conhecimentos adquiridos com os materiais disponibilizados e que quando um colega fazia um comentário preconceituoso, responsabilizando apenas a adolescente pela gravidez, as alunas argumentavam com clareza, disciplina, utilizando a norma culta da língua portuguesa, sem uso de palavrões, mesmo visivelmente indignadas com a fala dos colegas.

Um fato que também marcou o debate foi a não participação de alguns meninos nas discussões, os quais não se posicionaram no debate. Isso foi interpretado como timidez por se tratar de um tema que não é comumente tratado entre eles em sala de aula, falta de maturidade, ou por não entenderem a relevância da discussão. Alguns alunos explicavam que não tinham o que comentar, e que achavam que era culpa da adolescente que não se preveniu na relação sexual, expressando uma fala ainda preconceituosa. O debate evidenciou a importância do que os teóricos Dolz e Schneuwly destacaram sobre as fases do debate regrado, e que é possível em sala de aula mediar momentos de argumentação, mesmo de um tema polêmico com ideias discordantes; delimitando regras e um fechamento conclusivo, mesmo que sem consenso, com o envolvimento de grande parte da turma, sendo que até mesmo a ausência de participação foi interpretada e questionada pelos participantes. A mediação do professor e das estagiárias ocorreram em momentos de maior intensidade na explanação dos argumentos, primando por suscitar sempre reflexões mais profundas e relacionadas com o tema, lembrando os aspectos de tempo de fala de cada aluno/a para, assim as posições contrárias serem sempre revistas e reelaboradas pelos alunos. 
Os alunos, após o debate, relataram oralmente os aspectos relevantes do gênero, dificuldades encontradas e pontos positivos percebidos. Pontuaram como foi defender um ponto de vista contrário ao seu e como chegaram até essas conclusões. Num momento oportuno, os alunos assistiram ao vídeo do debate, fizeram a análise dos pontos abordados, avaliaram a participação dos membros e indicaram pontos a serem melhorados. Os/as alunos/as, após esse momento, decidiram que deveriam organizar a exposição do vídeo para a Semana Cultural da Escola, a fim de socializar com os demais membros da comunidade escolar a temática e o gênero debate regrado.

\section{Considerações finais}

As percepções mais relevantes com a atividade do debate regrado foram: quebra de paradigma de que os/as alunos/as não querem aprender na escola; descoberta de que o espaço escolar é rico de possibilidades e que, ao prepararmos uma aula, devemos sempre atentar para o protagonismo do/as aluno/as e incentivá-los/as para que eles/as se sintam envolvidos/as e participantes da sua aprendizagem.

Por fim, constatou-se que dar uma boa aula com alto índice de participação é possível, desde que seja planejada, pensada, que contenha atividades criativas, inclua novas tecnologias e diferentes abordagens sobre o mesmo tema. Além disso, a temática da aula deve estar conectada a questões sociais latentes nos/as alunos/as, como no caso dessa sequência didática, que abordou com o gênero debate regrado o tema da gravidez na adolescência, em conjunto com o exercício da oralidade, tendo em vista a cidadania.

Com a experiência da sequência didática, a partir da metodologia dos teóricos Schneuwly e Dolz (2011), foi possível perceber, na prática docente, sua importância e aplicabilidade. O método permite ao estagiário, ainda inseguro na docência, como também ao experiente professor, a percepção de que é possível uma melhor interação da teoria com a prática, muitas vezes dissociada e distanciada das salas de aula. $\mathrm{O}$ que se pode perceber é que a metodologia proposta pelos estudiosos pode auxiliar o/a professor/a que se vê diariamente desafiado/a a ensinar num momento histórico que desestimula a leitura, a escrita e mesmo a oralidade, devido ao aumento gradativo e acelerado das redes sociais. 0 professor deve compreender que as teorias como as de Schneuwly e Dolz (2011) estão disponíveis para o auxiliar no desafio de educar, ou melhor, de mediar, abordando assuntos complexos, como a gravidez na adolescência, atuando assim na formação do cidadão e da cidadã conscientes da sua importância na construção de uma sociedade melhor para todos e todas. 


\section{Referências}

BARCELLOS, C. Profissão Repórter: Gravidez na Adolescência. Disponível em < https://www.youtube.com/watch?v=N4RVm1yHYwo>. Acesso em 10 junho de 2019.

BNCC. Base Nacional Comum Curricular: Educação Infantil e Ensino Fundamental. Brasília: MEC/Secretaria de Educação Básica, 2017.

CEREJA, W.; COCHAR, T.. Português e Linguagens, $9^{\circ}$ ano. Editora Saraiva, p. 136-137 e 160-164, 2018.

DOLZ, J; SCHNEUWLY, B. Gêneros orais e escritos na escola. 3. Ed. Campinas, São Paulo: Mercado de Letras, 2011.

Google. Produtos. Google Sala de Aula. Disponível em <(https://edu.google.com/int/ptBR_ALL/?modal_active=none) >. Acesso em 10 de junho 2019.

SANTOS, S. N. G. Modos de Apropriação do Gênero Debate Regrado na Escola: uma abordagem aplicada. Universidade Federal do Pará, PA: D.E.L.T.A., 25:1, 2009 (39-66)

Data de submissão: 28/07/2020. Data de aprovação: 22/10/2020. 